\title{
ПРОБЛЕМЫ СОЗДАНИЯ АБСОРБЦИОННЫХ ХОЛОДИЛЬНЫХ АППАРАТОВ, РАБОТАЮЩИХ В УСЛОВИЯХ ПЕРЕМЕННЫХ ТЕМПЕРАТУР ВОЗДУХА ОКРУЖАЮЩЕЙ СРЕДЫ
}

\author{
А.П. Селиванов, преподаватель первой категории, соискатель \\ Одесский технический колледжс \\ А.С.Титлов, д.т.н., проф. \\ Одесская национальная академия пищевых технологий, г. Одесса
}

\begin{abstract}
Аннотация. На протяжении трёх лет была проведена серия опытов в условиях использования низкотемпературного потенциала окружающей среды с бытовым холодильником типа «ларь», оснащённым агрегатом абсорбционного типа. По результатам опытов был проведен анализ эффективности абсорбционного агрегата «сезонного» типа в сравнении с агрегатом, используемым в стандартных условиях, а также предварительное моделирование работы агрегата с целью определения перспективы применения потенциала окружающей среды для глобальной экономии энергоресурсов и возможности утилизации ненадёжных источников энергии в качестве движущей силы теплоиспользующей холодильной машины на протяжении длительного времени.

Annotation: For three years a series of experiences in conditions of use of low-temperature potential of environment with the household "chest" refrigerator equipped with the unit of absorbing type was carried out. By results of experiences the analysis of efficiency of the absorbing unit of "seasonal" type in comparison with the unit used in standard conditions, and also preliminary modeling of operation of the unit for the purpose of definition of prospect of use of potential of environment for global economy of energy resources and possibility of utilization of unreliable power sources as a driving force of the heat using refrigerator throughout a long time was carried out.
\end{abstract}

Ключевые слова: абсорбционная холодильная машина, холодильник «сезонного» типа, низкотемпературный потенциал окружающей среды, технологии «нечёткого» моделирования в многофакторных системах.

Постановка проблемы. Невозможно представить себе жизнь современного человека без использования искусственного холода во всех его проявлениях. Использование холодильников, морозильников, минихолодильников и кондиционеров является необходимым элементом быта каждой семьи. Вместе с тем анализ потребительского рынка бытовой холодильной техники на территории Украины и других государств постсоветского пространства показывает перенасыщение оборудованием ведущих фирм Европы, США, Юго-Восточной Азии и Японии в рамках агрессивной ценовой политики и практически полное отсутствие отечественных моделей по ценам, доступным основной части населения.

Экономическая ситуация в Украине не позволяет развернуть стабильное производство парокомпрессионной холодильной техники и обеспечить резкое увеличение выпуска бытовой холодильной техники по относительно низким ценам можно только за счёт моделей абсорбционного типа. Это связано с тем, что затраты на расширение и модернизацию их производства значительно ниже по сравнению с компрессионными аналогами, и, кроме того, себестоимость абсорбционных моделей до 50\% ниже из-за отсутствия в конструкции дорогостоящего компрессора и использования трубопроводов и теплообменных аппаратов из черных металлов

Также отсутствие компрессора определяет более высокую надёжность и ресурс абсорбционных моделей, а также их практическую бесшумность в работе [1].

Характерной особенностью абсорбционных холодильников является возможность использования для их работы различных неэлектрических источников энергии (газ, биогаз, керосин, бензин, сбросовое тепло и т.д.), а также возможность работы на электрических источниках низкого качества. Падение напряжения в сети до 160 В, что характерно для сельской местности, практически не оказывает влияния на их работоспособность.

Немаловажным аспектом разработок абсорбционных моделей является озонобезопасность их рабочего тела (водоаммиачная смесь и водород). Проблемы перехода на экологически безопасные хладагенты (поиск новых синтетических масел; низкая энергетическая эффективность новых экологически безопасных хладагентов; 
недостаточный профессиональный уровень разработчиков и обслуживающего персонала) заставляют разработчиков бытовой и торговой холодильной техники обращать пристальное внимание на холодильные аппараты с абсорбционно-диффузионными холодильными машинами (АДХМ).

Переход на озонобезопасные хладагенты, осуществляемый в бытовой холодильной технике, является довольно сложным и не может быть освоен большинством производителей даже мирового уровня.

Рабочее тело АДХМ - водоаммиачный раствор с добавкой «инертного» газа - водорода, гелия либо их смеси абсолютно экологически безопасно - имеет нулевые значения озоноразрушающего потенциала и потенциала «парникового» эффекта [1].

Основными раработчиками и производителями абсорбционной бытовой холодильной техники за рубежом являются европейские фирмы “Elektrosuisse-Valentini” (Италия), “Electrolux” (Швеция), имеющая также филиалы в Великобритании, Дании, Франции, Германии, Швейцарии, Люксембурге, Италии и “Sibir” (Швейцария) [2].

Производством бытовой абсорбционной холодильной техники заняты также фирмы [2]: “Smeg” (Италия), “Philips” (Голландия), “Camping Gas International” (Франция), “Blomberg”, "Bosch”, “Siemens”, “Bulka-Lehel” (Германия), “Caravell” (Дания), “Lehel” (Венгрия), “Polar” (Польша), “Uро Asko Оу” (Финляндия), “Sanyo” (Япония), "Brist" (Болгария).

В России специализированные производства развёрнуты также на заводах холодильников в Москве («Иней»), Санкт-Петербург («Ладога») и в Великих Луках («Морозко») [3]. Широкое распространение, например, получил простейший абсорбционный агрегат «Морозко-3М», схема которого изображена на рис.1 и который заслуженно может называться лучшим помощником из-за способности поддерживать надёжные характеристики в условиях нестабильного электроснабжения.

В Украине ведущим разработчиком и производителем бытовой абсорбционной холодильной техники до последнего времени являлся Васильковский завод холодильников (модели «Кристалл», «Киев») [2]. Однако в настоящее время по экономическим причинам производство приостановлено и рынок приобрёл острую нехватку недорогих отечественных бытовых холодильных аппаратов.

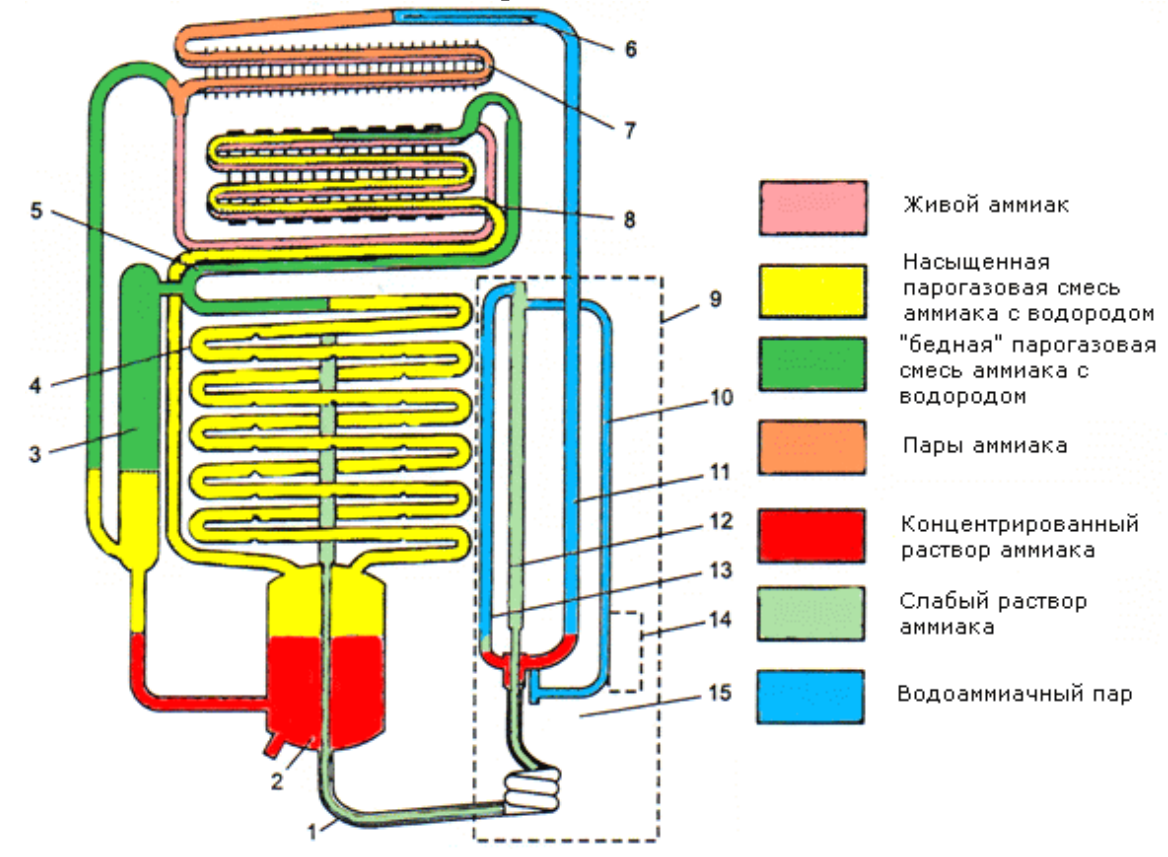

Рис. 1. Холодильный агрегат холодильника «Морозко-3М»:

1 - теплообменник; 2 - сборник раствора; 3 - аккумулятор водорода; 4 - абсорбер; 5 - регенеративный газовый теплообменник; 6 - дефлегматор; 7 - конденсатор; 8 - испаритель; 9 - генератор; 10 - термосифон; 11 - регенератор; 12 - трубки слабого раствора: 13 - пароотводящая трубка; 14 - электронагреватель; 15термоизоляция

В отличие от Украины в ассортименте моделей абсорбционной холодильной техники стран мира $70 \%$ от общего числа занимают холодильники объемом до 100 дм³ $^{3}$ а холодильники большей емкости, как правило, имеют 
неэлектрический источник приводной энергии. При этом рынок Европы ориентирован на выпуск моделей повышенной комфортности и, как следствие, повышенной стоимости, которые не являются единственным холодильным аппаратом в семье и направлен на средний класс населения с соответствующим уровнем дохода, характерным для жителей цивилизованных стран.

\section{Анализ последних исследований и публикаций.}

Последние мировые тенденции требуют пересмотреть эффективность применения упомянутой техники в расчётных режимах, поскольку, исходя из общефизических представлений, решать проблемы энергосбережения при эксплуатации бытовых абсорбционных холодильников и морозильников можно посредством [1]:

a) оптимизации цикла, схем, конструкций АХА и охлаждаемых камер, а также режимов работы АХП;

б) использования естественного низкотемпературного потенциала наружного воздуха в холодное время года для холодильного хранения продуктов и для отвода бросового тепла холодильного цикла.

В первом направлении проведена колоссальная работа учеными и разработчиками всего мира и в области схемноцикловых решений, а также конструкций теплообменного оборудования и объектов охлаждения на сегодняшний момент используются самые передовые технологии, определяющие высокую степень совершенства изделия.

Существующие разработки в области использования низкотемпературного потенциала окружающей среды позволяют, к примеру, при помощи диодных испарительно-конденсационных систем, установленных в стенке здания с некоторым углом наклона к горизонту, осуществлять тепловую связь с воздухом окружающей среды [1]. Это предложение может найти применение в северных регионах, где $7 \ldots 8$ месяцев в году температура наружного воздуха значительно ниже $0{ }^{\circ} \mathrm{C}$.

Использовать естественный холод для хранения пищевых продуктов в настоящее время предлагают разработчики теплонасосной «системы ХОЛТ» (по оригинальной терминологии разработчиков - «холодильник - теплильник» [1]), с выносом всего или части холодильника в окружающую среду.

Следует отметить, что терминология в этом направлении разработок еще не сложилась, и имеют место и другие названия, например, разработчики абсорбционной холодильной техники НПО прикладной механики (Железногорск, Российская Федерация) применяют термин «сезонный холодильник» [2].

Системы ХОЛТ комплектуются парокомпрессионными холодильными аппаратами либо термоэлектрическими батареями. Для исключения перемораживания продуктов и предотвращения загустения масла в компрессоре используются специальные нагревательные элементы и система терморегулирования. Аппараты предлагают размещать в оконных проемах так, чтобы одна из стенок холодильной камеры выходила в окружающую среду. Утверждается [2], что системы «ХОЛТ» позволят снизить годовые энергозатраты при эксплуатации холодильного прибора на $50 . .66 \%$.

Более приспособлен для работы в составе «сезонного холодильника» АХА. Во-первых, отсутствуют проблемы загустения масла в компрессоре в нерабочий период, а во-вторых, появляется возможность значительно повысить энергетическую эффективность безнасосного теплоиспользующего цикла за счет снижения общего давления в системе и дополнительного переохлаждения потоков жидкого аммиака на входе испарителя и слабого ВАР на входе абсорбера [3].

Необходимо отметить, что в настоящее время уже имеются разработки по способам управления АХА в случаях, когда теплорассеивающие элементы и генераторный узел расположены за пределами отапливаемых помещений, т.е. находятся при температуре наружного воздуха, в том числе и по способам запуска АХА при температуре воздуха ниже минус $10{ }^{\circ} \mathrm{C}[3]$. Актуальность создания сезонного холодильника определяется проблемами энергосбережения при эксплуатации бытовых и торговых холодильных приборов.

Цель исследования - исследование возможности эффективного использования низкотемпературного потенциала окружающей среды в работе бытовых теплоиспользующих холодильных агрегатов абсорбционного типа.

\section{Изложение основного материала.}

Современное бытовое и торговое холодильное оборудование проектируется для работы в «жестком» режиме эксплуатации для данных климатических условиях (в Украине - это обеспечение нормативных температурных параметров в холодильной камере при температуре воздуха в помещении $32{ }^{\circ} \mathrm{C}$ [2]). В то же время в нашем умеренном климате основное время эксплуатации аппаратов бытовой и торговой техники проходит при температуре воздуха в помещении $16 \ldots 22^{\circ} \mathrm{C}$. При таких температурах воздуха холодильные аппараты работают не постоянно, а с 
периодическими отключеньями, т.е. в позиционном режиме. При более низких температурах воздуха в помещении (менее $10{ }^{\circ} \mathrm{C}$ ) эксплуатация современных бытовых и торговых холодильных приборов не рекомендуется.

Анализ результатов экспериментальных исследований опытных и серийных моделей абсорбционных холодильников показал, что их повышенный, по сравнению с компрессионными аналогами, уровень энергопотребления предопределяется существующей методологией расчета и способом управления при эксплуатации. В соответствии с существующими требованиями к бытовым холодильным аппаратам, в первую очередь, необходимо обеспечить заданный температурный режим в холодильной камере в «жестком» режиме эксплуатации, при этом, как правило, работа АХА осуществляется в непрерывном режиме - при коэффициенте рабочего времени равном единице (КРВ = 1), а значение энергопотребления во внимание не принимается.

При таком подходе теплоорассеиваюшие элементы АХА обладают запасом поверхности в условиях эксплуатации при умеренных $\left(18 . .25^{\circ} \mathrm{C}\right)$ и низких температурах окружающей среды.

Запас поверхности позволяет повысить холодопроизводительность испарителя АХА за счет: дополнительного переохлаждения жидкого аммиака в конденсаторе; повышения степени очистки парогазовой смеси (ПГС) в абсорбере; снижения температуры ПГС на входе в испаритель.

При низких температурах окружающей среды паровой поток аммиака лишь частично заполняет конденсатор, а равновесная концентрация аммиака в жидком водоаммиачном растворе (ВАР) смещается в область низких давлений. Оба эти фактора вызывают снижение полного давления в системе и рост интенсивности диффузионных процессов при испарении и абсорбции, что дополнительно приводит к росту холодопроизводительности испарителя.

К отрицательным моментам работы АХА в условиях умеренных и низких температур окружающей среды следует отнести: частичную конденсацию паров аммиака в дефлегматоре; переохлаждение крепкого (насыщенного аммиаком) ВАР на входе в жидкостном теплообменнике (ЖТО); рост тепловых потерь с элементов генераторного узла.

Все эти факторы при неизменной величине подводимой тепловой нагрузки на генератор-термосифон приводят к снижению подачи аммиака в испаритель, т.е. вызывают снижение холодильной мощности.

Результирующее воздействие на холодопроизводительность испарителя АХА температур окружающей среды определяется особенностями конструкции, режимами и условиями эксплуатации холодильного аппарата.

Несмотря на многофакторность воздействия температуры окружающей среды на работу элементов АХА однозначным является ее влияние на значения теплопритоков в охлаждаемые камеры, т.е. на значение требуемой холодопроизводительности в режиме хранения.

Так, при эксплуатации холодильной камеры с уровнем температур хранения плюс $5{ }^{\circ} \mathrm{C}$ в помещении с температурой $19^{\circ} \mathrm{C}$ требуется примерно в два раза меньшая холодопроизводительность, чем в «жестких» условиях эксплуатации.

При создании сезонного холодильника абсорбционного типа необходимо принимать во внимание характерные особенности пускового периода в режиме позиционного управления. И высокая инерционность системы заставляет в серьёз задуматься о создании специализированных систем регулирования на базе пропорционально-интегральнодифференциальных (ПИД) регуляторов [1].

Авторами статьи были проведены опытные исследования торгово-бытового холодильника типа «ларь» вместимостью 100 дм $^{3}$ на базе абсорбционного холодильного агрегата производства Васильковского завода холодильного оборудования. Холодильник был установлен в неотапливаемом и неохлаждаемом помещении. Контролировались: температурное поле охлаждаемого объёма, температура на верхнем участке генераторного узла, температура конденсации, температура абсорбции, параметры электрической сети, потребляемая мощность. На первоначальном этапе проведения опытов применено простейшее позиционное регулирование с параметром настройки минус $18{ }^{\circ} \mathrm{C}$. Температурный режим связан с областью применения исследуемого образца. Холодильный «ларь» (рис.2) применяется, как правило, для долгосрочного хранения замороженных продуктов. Подобные объёмы и режимы хранения характерны для частных хозяйств или потребителя среднего уровня достатка, делающего запасы на перспективу. То есть охватывается тот социальный слой, который на сегодняшний момент находится в маркетинговом провале. Иными словами, нуждается в качественном холодильном оборудовании, которое им не в состоянии предоставить ведущие мировые производители по умеренным бюджетным ценам.

Возможность получения надёжных характеристик была исследована в широком диапазоне параметров электрической сети, моделируя ненадёжность подачи питания. Исследованию также подлежали равномерность температурного поля в камере и экономия использования абсорбционного бытового холодильника в качестве «сезонного». 


\section{ТЕХНІЧНІ ЗАСОБИ І ІНФОРМАЦІЙНІ ТЕХНОЛОГІЇ У СИСТЕМАХ УПРАВЛІННЯ}

Генераторный узел, работая в позиционном режиме, дал классические характеристики, широко описанные в литературе, оптимизация и автоматизация которых хорошо известны.
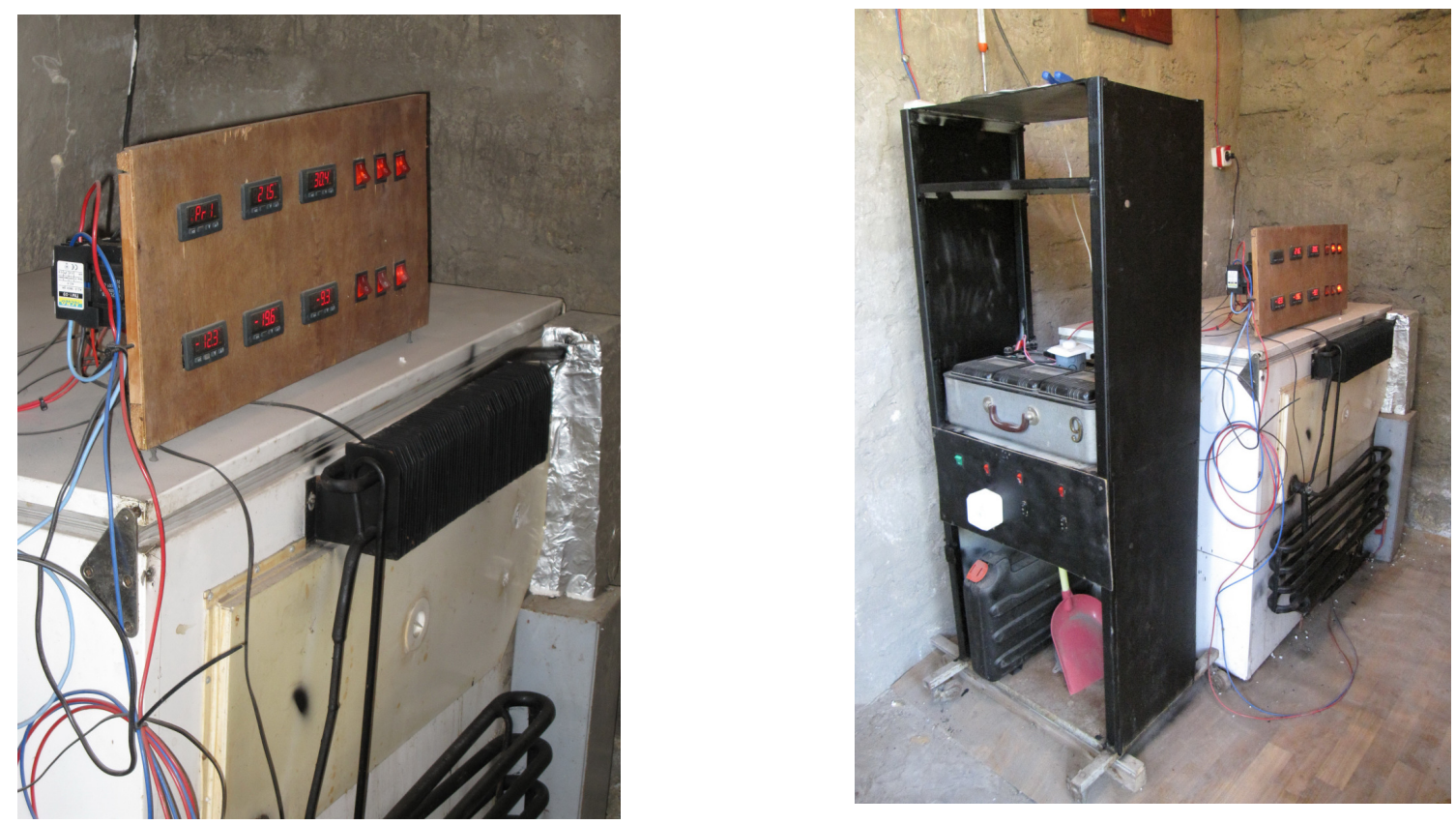

Рис.2. Внешний вид лабораторного стенда на базе абсорбционного холодильника типа «Ларь» вместимостью охлаждаемого объёма 100 дм³ $^{3}$

Сезонно усредненные температурные уровни агрегата представлены на рис.3.

Температурные колебания

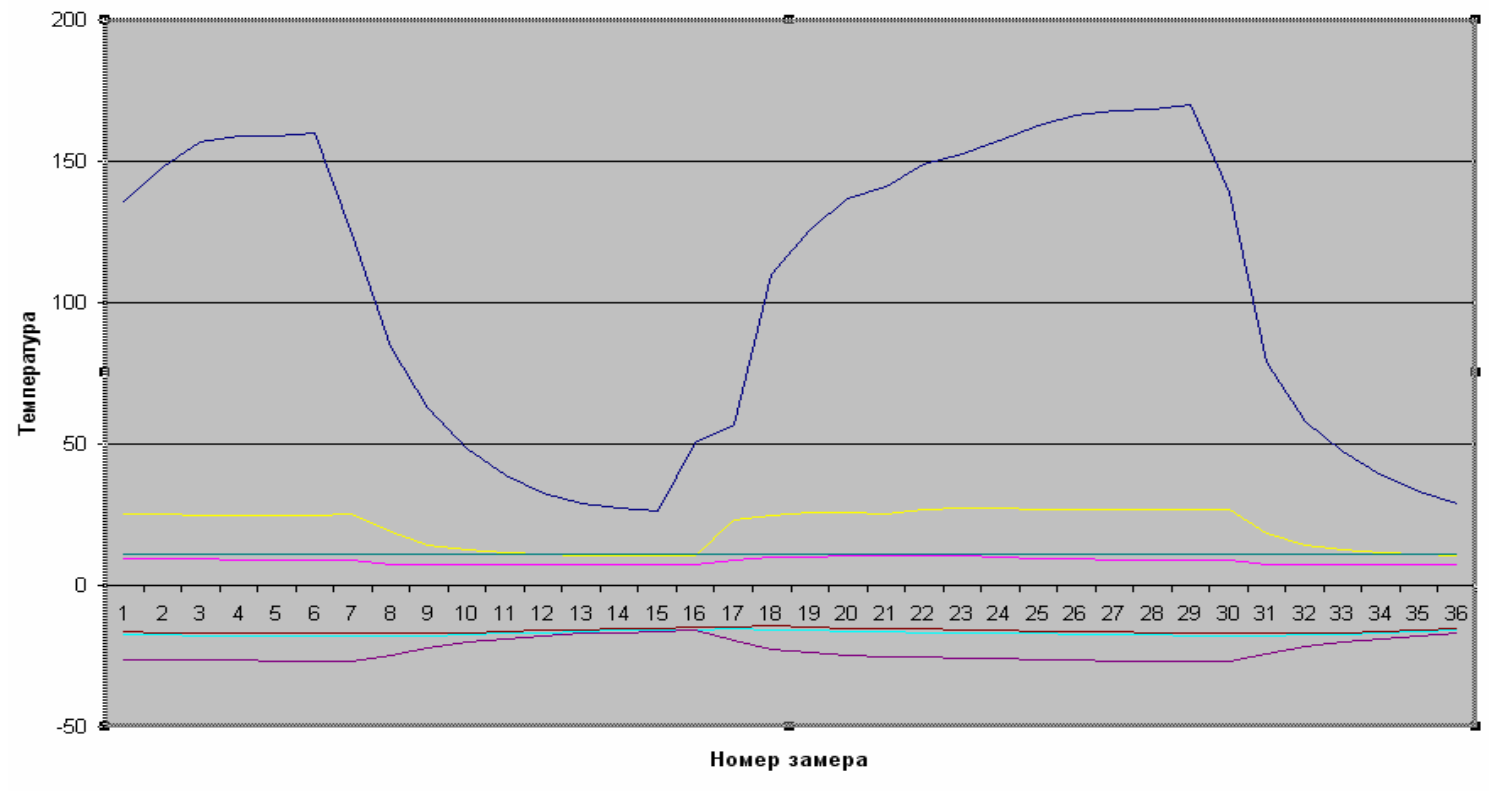

Рис.3. Усредненные температурные поля исследуемого холодильного агрегата. 
По результатам проведения опытов в течении трёх лет были получены статистические данные и сделаны следующие обобщенные выводы:

1. Использование суточного и сезонного изменения температуры окружающей среды дает значительное повышение энергосберегающего эффекта (до $35 \%$ при параметре настройки $-18{ }^{\circ} \mathrm{C}$ );

2. Проведены исследования низкотемпературного абсорбционного холодильного агрегата (НТХА) при естественном и принудительном обдуве конденсатора. Полученные данные показали энергетическую неэффективность принудительного обдува теплорассеивателей холодильного аппарата;

3. Проведены исследования при теплоизолированном и нетеплоизолированном подъемном участке дефлегматора. Описаны зависимости и сезонные рекомендации по обслуживанию абсорбционного «сезонного» холодильника;

4. Задача аккумулирования холода напрямую не решалась. Однако выравнивание температурного поля производилось за счёт заполнения охлаждаемого объема продуктом;

5. Поддержание параметра настройки (минус $\left.18{ }^{\circ} \mathrm{C}\right)$ производилось двухпозиционном автоматическом режиме, поэтому значения коэффициента рабочего времени (КРВ) в течение опытного периода изменялось от нуля до единицы.

Однако отдельной проблемой стало поддержание равномерности температурного поля (рис.4) в охлаждаемом объёме. Отсутствие специальных холодоаккумуляторов, неэффективность теплоизоляции и уплотнения, а также работа на пониженных напряжениях, дали неравномерность, что является вполне решаемой проблемой для агрегата подобного типа.

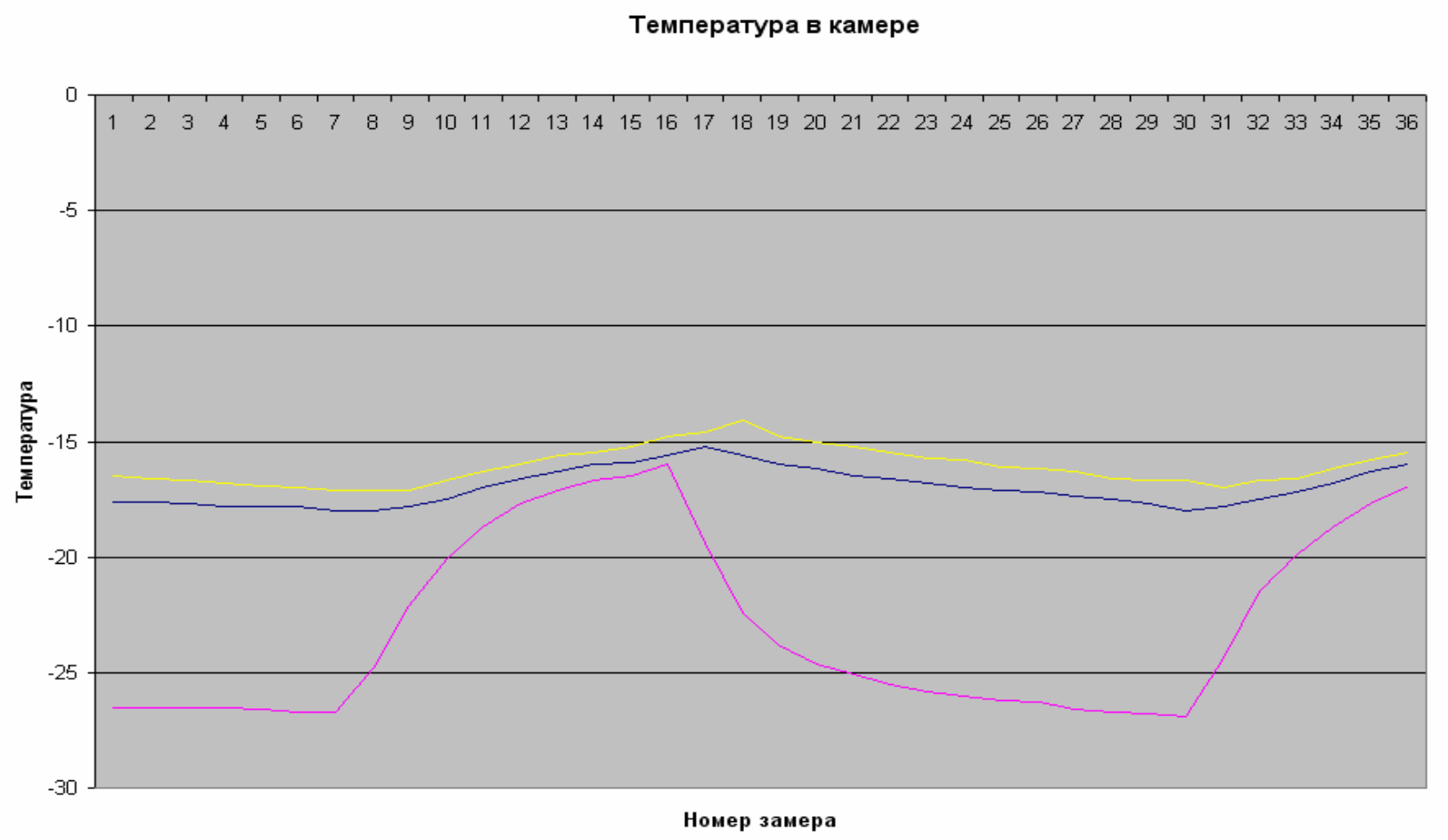

С одной стороны позиционность процесса кипения в испарителе определяет температурные колебания стенки камеры у испарителя. С другой стороны - инерционность общего объёма камеры практически сглаживает эти колебания и дополнительные устройства в практическом использовании очевидной выгоды не приносят. Однако в плане опыта использование тепловых труб может дать положительный результат.

Проблемы управления сложным объектом, которым является холодильная машина, сложны и многофакторны. Управление может быть направлено как на явление, процесс так и на конкретный объект.

Основными характеристиками сложного объекта можно считать отсутствие математического описания; стохастичность поведения, которая обусловлена сложностью объекта; «нетерпимость» к управлению; нестационарность - чем сложнее объект, тем быстрее он меняется [4]. 
Классические методы управления хорошо работают при полностью детерминированном объекте управления и детерминированной среде, а для систем с неполной информацией и высокой сложностью объекта (большом количестве внешних и внутренних факторов воздействия) оптимальными являются нечёткие методы управления. Это связано с тем, что стандартный, выпускаемый промышленностью агрегат, эксплуатируется в нестандартных условиях с большим количеством внешних и внутренних факторов, что в общем нарушает классическую модель управления. В такой ситуации упомянутые выше ПИД-системы не могут быть применены в полном объёме из-за отсутствия математического аппарата описания нестационарных процессов в системе. Поэтому применение аппарата нечёткой логики может оказаться одним из немногих возможных вариантов создания адекватной модели работы и управления сложным объектом.

Архитектура или модель нечёткого управления основана на замене классической системы управления системой нечёткого управления, в качестве которой используются системы нечёткого вывода. Одним из наиболее часто применяемых алгоритмов является алгоритм Мамдани, который включает следующие этапы: формирование базы правил систем нечёткого вывода, фаззификация входных переменных, агрегирование подусловий в нечётких правилах, активизация подзаключений в нечётких правилах, аккумуляция заключений нечётких правил, дефаззификация выходных переменных [5]. Формирование субъективных параметров управления в системах нечёткого регулирования зачастую является более гибкой и адекватной системой управления, чем классические методы математического моделирования.

\section{Выводы.}

1. По результатам проведенных опытов сформирована база данных, характеризующих и сравнительную (сезонную) экономичность и режим работы абсорбционной холодильной машины, использующей низкотемпературный потенциал окружающей среды;

2. Требуется сформировать рекомендации по проектированию и конструированию современных АХА торговобытового назначения, работающих в широком диапазоне температур окружающей среды;

3. Требуется завершить описание работы исследуемого образца при применении тепловых труб для выравнивания температурного поля по объёму холодильной камеры;

4. Требуется создание математической модели влияния локального и годового изменения температуры окружающей среды на параметры работы и энергосберегающие свойства «сезонного» НТАХА;

5. Требуется создание модели регулирования с учётом нечёткой фаззификации входных и выходных параметров абсорбционного агрегата «сезонного» типа;

6. Требуется проведение маркетинговых исследований для подтверждения необходимости разработки «сезонного» холодильного аппарата с целью популяризации среди производителей бытовой и торговой холодильной техники абсорбционного оборудования.

\section{Литература:}

1.Титлов А.С. Научно-технические основы создания энергосберегающих бытовых абсорбционных холодильных приборов: дис...д-ра техн. наук: 05.05.14 / Титлов Александр Сергеевич. - Одесса, 2008. - 447 c.

2.Васылив О.Б. Оптимизация режимов работы аппаратов различного функционального назначения с абсорбционно-диффузионными холодильными машинами: дис... канд. техн. наук: 05.04.03 / Васылив Олег Богданович - Одесса, 1998. - 228 с.

3.Титлов А.С. Пути повышения энергетической эффективности бытовых абсорбционных холодильных приборов / А.С. Титлов // Зб. наук. праць I - ої Міжнарод. наук.-техн. конф. «Холод в енергетиці і на транспорті: сучасні проблеми кондиціонування та рефрежерації» Частина 1. - Миколаїв: НУК, 2008. - С. 188 - 203 (додаток до наук.-техн. зб. "Збірник наукових праць Національного університету кораблебудування". 2008. - № 3).

4.Растригин Л.А. Современные принципы управления сложными объектами. - М: Сов. Радио, 1980.

5.Леоненков А.В. Нечёткое моделирование в среде Mathlab и FuzzyTech. - СПб.: БХВ-Петербург, 2003. 